\title{
O Humano Integrado Abordagens de Antropologia Teológica
}

Petrópolis: Vozes, 2007 - Formato (16,0 x 23,0) - 295 páginas

Alfonso García Rubio (organizador), Ana Maria de Azeredo Lopes Tepedino, Celso Pinto Carias, Cláudio de Oliveira Ribeiro, Joel Portella Amado, Lúcia Pedrosa de Pádua, Marcos Antônio de Santana, Maria Carmen Castanheira Avelar, Maria Joaquina Fernandes Pinto , Olga Consuelo Vélez Caro

\section{Introdução}

O HUMANO INTEGRADO- Abordagens de Antropologia Teológica é o primeiro livro conjunto de teólogos que se doutoraram na PUC-Rio, sob a orientação do Prof. Dr. Alfonso García Rubio. Os 10 autores criaram um círculo de estudos - Círculo do Rio-, para desenvolver a pesquisa e a publicação de textos no âmbito da teologia e da pastoral. Nesta obra, O Humano Integrado, são apresentadas reflexões teológicas sobre diferentes temáticas, tendo como eixos de convergência a antropologia teológica e a visão integrada do ser humano, herdada das tradições bíblico-cristãs. Os capítulos procuram articular, de modo inclusivo, as diversas dimensões do humano e da vida, defendendo a riqueza da proposta de salvação cristã que valoriza a complexidade do ser e do agir humano. Os autores fazem um diálogo crítico com outras ciências, com a cultura moderna / pós-moderna e utilizam contribuições de outras áreas do conhecimento.

Resumindo, podemos afirmar que o livro procura enfrentar, no campo da antropologia, o desafio teológico-pastoral, proveniente do recente incremento; no âmbito das Igrejas, os de dualismos e reducionismos, antigos e modernos, que empobrecem gravemente o significado da salvação cristã. Em especial, preocupa aos autores o aparecimento e a rápida expansão de movimentos religiosos inspirados numa visão imediatista, dicotômica e individualista da salvação levando a expressões de fé reducionistas e mutiladoras do ser humano e da vida cristã. Por isto é comum em todos os capítulos a pro- 
posta de humanização integral contida na revelação bíblico-cristã e que se dirige também a homens e mulheres da época moderna/pós-moderna. $\mathrm{O}$ enfoque da espiritualidade e da Pastoral enriquece as reflexões desenvolvidas.

Uma rápida apresentação dos 10 capítulos ajuda os leitores a perceberem a perspectiva antropológica do livro, a preocupação -comum aos autores- de abertura ao diálogo transdisciplinar e o realce dado à espiritualidade e à pastoral. Depois da apresentação minuciosa e completa da obra, feita pelo prof. Alfonso García Rubio, seguem-se os capítulos, em cuja seqüência pode-se perceber o encadeamento temático e o pano de fundo antropológicopastoral.

\section{Realmente livres? A ambigüidade antropológica dos ambientes urba- nos (Joel P. Amado) \\ O capítulo analisa o risco do reducionismo na evangelização, em am-} bientes urbanos (industriais e, sobretudo, pós-industriais). Realça o processo de inculturação na ação evangelizadora porque, quando esta falha, nos ambientes urbanos pós-industriais, desenvolvem-se produções religiosas que tendem a reunir consumidores de eficácias religiosas muito mais do que a criar fraternidade e comunidade real. "É preciso partir da perspectiva predominante -a individual- para, privilegiando a via do afeto, chegar ao comunitário e ao social: individualidade aberta à alteridade (dimensão comunitária)".

\section{O ser humano diante de suas situações-limite: uma reflexão teológica em Paul Tillich (Cláudio de Oliveira Ribeiro)}

O capítulo desenvolve, em sintonia com a reflexão teológica de Paul Tillich, uma análise sobre a forte expansão, supra-confessional, de uma religiosidade que procura evitar ou suprimir as fragilidades humanas. $\mathrm{O}$ autor critica a visão de religião como "solução" imediata para os problemas cotidianos, decorrente da tentativa de suprimir os limites da existência humana ("situações-limite"), afirmando que "não é negando essas situações que o ser humano pode ser salvo", porque "a experiência da salvação se dá no coração delas".

3. Fé cristã: resposta humana à iniciativa amorosa de Deus (Celso Pinto Carias)

O autor ressalta o substrato antropológico do ato de fé cristã, visando reforçar seu caráter humanizador e, assim, ajudar no discernimento pastoral que vem sendo desafiado por reducionismos e unilateralismos atuais. Focaliza, em especial, o impacto sobre a fé cristã da realidade cultural atual "que tende a uma crescente subjetivação da vida humana" com o conseqüente 
perigo de transformar a experiência cristã de fé em "mero lenitivo para resolver uma situação específica que não engloba a vida toda". Da pergunta: "de qual Deus se fala, na efervescência religiosa atual? Surge a necessidade da volta ao Deus revelado mediante Jesus Cristo, exigência teológicopastoral básica.

\section{Pressupostos epistemológicos para uma visão de sujeito integral (Olga Consuelo Vélez Caro)}

A autora fundamenta-se na reflexão de B. Lonergan para aproximar o leitor do sujeito integral, traçando um lúcido itinerário para desenvolver um modo de conhecer articulado com o conjunto da existência humana, especialmente com o mundo afetivo tão esquecido por racionalismos antigos e modernos. A articulação entre as diversas dimensões do ser humano mostra que, para conhecer, "não basta experimentar, entender e julgar (concepção tradicional). Um quarto nível se faz necessário: o da decisão, da responsabilidade, do agir moral, em relação ao valor do que é experimentado, entendido e julgado, uma vez que o sujeito humano é capaz de conhecimento e de ação moral".

\section{Articulação entre espiritualidade e ética na trajetória cristológica da comunidade joanina (Ana Maria de Azeredo Lopes Tepedino)}

O capítulo analisa o processo cristológico vivido pela comunidade joanina, mostrando como a fidelidade no seguimento de Jesus Cristo supera os dualismos excludentes que prejudicam a riqueza da vida cristã. Nesse itinerário critológico, a comunidade vive uma caminhada em que se encontram, de maneira fecunda, a espiritualidade e o compromisso ético, numa perspectiva de integração antropológica no pólo oposto do dualismo e do racionalismo: nada de mística sem profetismo e nada de profetismo sem mística, mas uma articulação fecunda entre essas duas realidades da vida cristã individual e comunitária.

\section{Teologia e Pedagogia em diálogo (Maria Carmen Castanheira Avelar)}

A autora mostra a importância de a teologia superar o reducionismo racionalista, para resgatar suas diferentes funções e abrir-se à transdisciplinaridade. O diálogo entre Pedagogia e Teologia, realizado no eixo comum da antropologia, pode ser um caminho de humanização e revitalização para ambas. A pedagogia pode oferecer à teologia pistas para o aprimoramento das metodologias de trabalho, das formas de linguagem e de comunicação. Teresa de Ávila aparece no capítulo como exemplo de teóloga / pedagoga que teve sucesso nesta parceira. A grande teóloga e mestra espiritual ultra- 
passa as barreiras entre indução e dedução, entre teoria (fides quae) e prática (fides qua), mantendo a capacidade de admiração, de comunicação, de narrativa afetuosa e sedutora.

\section{Espiritualidade integradora: o testemunho privilegiado de Santa Te- resa de Ávila (Lúcia Pedrosa de Pádua)}

A autora trabalha o desafio da articulação da antropologia teológica integrada com a espiritualidade, seguindo o itinerário de Teresa de Ávila. Os vários níveis de integração analisados na experiência teresiana: entre o mundo interior e a ação histórica, entre corpo, mente e espírito, oração e ação, real e ideal, razão e afeto, morte e vida, solidão e comunitariedade, humano e divino, constituem um rico itinerário de amadurecimento cristão. Alicerçado numa visão unitária do ser humano, este processo espiritual fundamenta-se no caminho da verdadeira humanidade encontrada em Jesus Cristo em quem o dualismo antropológico é superado, radicalmente, e a espiritualidade passa a ser vivida na fecunda relação das dimensões constitutivas da pessoa humana.

\section{Cristologia sem dualismo: implicações antropológicas à luz da refle-} xão de Wolfhart Pannenberg (Marcos Antônio de Santana)

O autor analisa a relação entre cristologia "do alto" e cristologia "de baixo" na reflexão do Novo Testamento, focalizando os evangelhos e a cristologia paulina na qual "não há oposição entre o crucificado e o ressuscitado, assim como não há entre o ressuscitado e o preexistente. Trata-se sempre do único Jesus Cristo". O método cristológico de W. Pannenberg, que relaciona a visão integrada do ser humano com a abertura dialógico-crítica à cultura moderna, é um forte exemplo de articulação adequada entre as cristologias ascendente e descendente. $\mathrm{O}$ capítulo apresenta, então, as implicações antropológicas da cristologia que articula, satisfatoriamente, o movimento de "baixo" para o "alto", próprio da reflexão de W. Pannenberg. Essa cristologia pode contribuir para superar, no contexto eclesial latino-americano, os unilateralismos que empobrecem gravemente o trabalho pastoral e a espiritualidade. Por isto, a circular idade entre a antropologia de integração e uma cristologia integrada e integradora é uma das necessidades básicas da reflexão teológica atual.

9. Sexualidade e salvação: realidades opostas? (Maria Joaquina Fernandes Pinto)

A autora procura identificar o caráter salvífico que pode ter a sexualidade humana, do ponto de vista cristão. Ilumina sua reflexão pela abordagem 
filosófica de E. Lévinas. Realça a importância da sexualidade humanizada, vivida como ascese e espiritualidade, como um chamado, um desejo do outro para comunicar, intercambiar, comungar. Essa visão não esvazia a dimensão procriativa da sexualidade, mas, ao contrário, dá-lhe sentido humano. Ou seja, a sexualidade não se reduz à atividade genital, mas constitui uma força de encontro, de comunhão e de criatividade que impregna toda a pessoa e toda a sua vida. Jesus Cristo, nosso Deus feito-carne-sexuada, é o modelo da vivência de uma sexualidade humanizada que aponta para a superação radical da oposição-exclusão dualista entre sexualidade e salvação.

\section{Novos rumos da antropologia teológica cristã (Alfonso García Rubio)}

No capítulo final, o organizador da obra, tendo como pano de fundo a crítica e a superação do dualismo bem como a adoção de uma visão integrada do ser humano, apresenta uma espécie de estado da questão das tentativas, por parte da antropologia teológica cristã, de abertura crítica ao mundo da ciência e da cultura atual, especialmente pós-moderna. Resssalta, em primeiro lugar, a importância do dinamismo eclesial na abertura dialógicocrítica ao mundo cultural grego, que possibilitou a clarificação da originalidade do Deus cristão. Um Deus solidário em que a relação é tão importante, tão divina, quanto à substância/natureza. Concomitantemente, desenvolvese a visão do ser humano como pessoa, como liberdade relacionada, como alguém, chamado a dar sentido à própria vida. Esta é a visão presente nos trabalhos da antropologia teológica que, hoje, tenta escutar e realizar um diálogo crítico com as ciências tais como a astrofísica, a física, a biologia e a psicanálise. O autor prossegue, chamando a atenção para a perspectiva holística e as características próprias da sensibilidade pós-moderna, para a mudança em andamento na compreensão e na explicitação da fé em Deus criador e no ser humano criado à imagem d'Ele. Enfatiza, na abordagem da fé, o aspecto da liberdade em Deus e da autonomia das coisas criadas, o aspecto da liberdade relacionada, criativa e criadora, construtora do sentido da vida. No item conclusivo são apresentadas algumas repercussões teológicopastorais dos novos rumos da antropologia teológica.

\section{Conclusão}

Pode-se concluir, afirmando que O Humano Integrado dirige-se a quem, de algum modo, esteja comprometido com a Teologia, em especial, no nível universitário: professores, agentes evangelizadores-clérigos e leigos-, e pessoas interessadas no diálogo entre a fé cristã e as ciências, a cultura e a sociedade, notadamente sob o prisma antropológico. Certamente, como afirma o prof. Alfonso García Rubio, "a prioridade concedida à visão 
unitária do ser humano visto como portador de sentido, chamado a criar algo novo na história e no cosmo, em conexão com o enriquecimento da reflexão teológica resultante da abertura e do diálogo com outros saberes, repercute, fortemente, na compreensão e na vivência da espiritualidade cristã e da ação pastoral.

Maria Carmen Castanheira Avelar Professora da Cultura Religiosa e da Teologia a Distância, do Departamento de Teologia da PUC-Rio Doutora em Teologia Sistemático-Pastoral 